\title{
Genetic studies in human and murine giardiasis*
}

\author{
I C ROBERTS-THOMSON, $\dagger$ G F MITCHELL, R F ANDERS, B D TAIT, P KERLIN, \\ A KERR-GRANT, AND P CAVANAGH
}

From the Department of Gastroenterology and the Tissue Typing Laboratory, The Royal Melbourne Hospital; the Laboratory of Immunoparasitology. The Walter and Eliza Hall Institute of Medical Research; the Department of Gastroenterology, The Queen Elizabeth Hospital, Adelaide; and the Department of Microbiology, Fairfield Hospital, Melbourne, Australia

SUMMARY Genetic markers were analysed in 48 adults who appeared to have a prolonged infection with Giardia lamblia. The frequency of ABO blood groups, Rhesus blood groups, and Gm phenotypes was similar to that in control subjects. However, there was a higher than expected frequency of HLA antigens A1 (observed 46.7\%, expected 32\%) and B12 (observed $47.8 \%$, expected $25.8 \%$ ) and a higher than expected frequency of the phenotypes A1/A2 and B12/B27. Genetic studies were also performed with inbred strains of mice showing relatively rapid (BALB/c) and defective $(\mathrm{C} 3 \mathrm{H} / \mathrm{He})$ spontaneous elimination of Giardia muris. From analyses in backcross mice several genes appeared to influence susceptibility to prolonged infection with $G$. muris.

Individuals infected with Giardia lamblia show considerable variation in the duration of infection and the severity of symptoms. In a study of the natural history of $G$. lamblia in volunteers, ${ }^{1} 12$ of 14 adults showed spontaneous elimination of infection, while two had continuing cyst excretion for at least four months. Similarly, symptoms are minimal or absent in some patients, while others have severe diarrhoea sometimes accompanied by steatorrhoea, weight loss, and hypoalbuminaemia. ${ }^{2} 3$ Factors such as humoral immune deficiency ${ }^{4}$ and previous gastrectomy ${ }^{5}$ may predispose to severe and prolonged symptoms but these associations are relatively unusual. Genetic factors may be of importance, as two studies in infected children showed a higher than expected frequency of blood group A. ${ }^{6}$ ?

Studies with $G$. muris infection in inbred strains of mice ${ }^{8}$ illustrate the potential importance of genetic factors. Whereas BALB/c mice show spontaneous resolution of infection in four to six weeks, $\mathrm{C} 3 \mathrm{H} / \mathrm{He}$ mice have a prolonged infection with high cyst counts in stools for several months. Spontaneous resolution of infection has a dominant mode of inheritance, as $\mathrm{BALB} / \mathrm{c} \times \mathrm{C} 3 \mathrm{H} / \mathrm{He} \mathrm{F}_{1}$

\footnotetext{
*This work was supported by the Victor Hurley Medical Research Fund of The Royal Melbourne Hospital, the National Health and Medical Research Council of Australia, and The Rockefeller Foundation.

†Address for correspondence: Dr I C Roberts-Thomson, Department of Gastroenterology, Royal Melbourne Hospital, Victoria, Australia, 3050 .

Received for publication

December 1979
}

mice show a similar pattern of infection to that in $\mathrm{BALB} / \mathrm{c}$ mice.

In the present study the frequency of genetic markers has been analysed in adults with prolonged giardiasis. In addition, the pattern of $G$. muris infection has been evaluated in backcross $\mathrm{F}_{1} \times \mathrm{C} 3 \mathrm{H} / \mathrm{He}$ mice (where genes can be expected to be segregating) in an attempt to determine the number of genes influencing resistance to infection.

\section{Methods}

\section{HUMAN STUDIES}

Genetic factors were determined in 48 adults of British (39) or European (nine) origin in whom prolonged infection with $G$. lamblia seemed likely. There were 20 females and 28 males with an age range of 16 to 65 years. Thirty-six patients had gastrointestinal symptoms, principally diarrhoea, which had been continuing for at least eight weeks and which improved after treatment with metronidazole. Twelve patients were infected in the absence of symptoms and in these patients prolonged infection was assumed. In all patients, giardiasis was confirmed by the presence of Giardia cysts in stools or the presence of trophozoites in a small bowel aspirate, biopsy imprint, or histological sections of small bowel. Thirty-three patients were identified at two hospitals in Melbourne and 15 in a survey of the prevalence of giardiasis in South Australia.9 Eleven patients gave a history of overseas travel 
Table 1 Disorders associated with prolonged giardiasis (15 patients)

\begin{tabular}{ll}
\hline Disorder & (no.) \\
\hline Hypogammaglobulinaemia & 3 \\
Hypogammaglobulinaemia with NLH & 1 \\
Dysgammaglobulinaemia & 2 \\
IgA deficiency & 1 \\
IgA deficiency with NLH and PA & 1 \\
Partial gastrectomy & 2 \\
Diabetes mellitus & 2 \\
Chronic renal failure & 2 \\
Cryptogenic cirrhosis & 1 \\
Hodgkin's disease & 1 \\
Asthma (on corticosteroid drugs) & 1 \\
Ulcerative colitis & 1 \\
Breast cancer & 1 \\
Thyrotoxicosis & 1 \\
\hline
\end{tabular}

NLH: nodular lymphoid hyperplasia.

PA: pernicious anaemia.

before the onset of symptoms. Fifteen patients had associated chronic disorders as outlined in Table 1. Severe symptoms accompanied by marked weight loss and hypoalbuminaemia occurred in two patients with prior gastrectomy.

$\mathrm{ABO}$ and Rhesus blood groups were determined by standard haemagglutination techniques, while HLA typing was performed using the microlymphocytotoxicity technique of Terasaki. ${ }^{10}$ HLA typing was performed at Melbourne and Adelaide and in both centres at least 23 antigens were defined. Genetic markers on the heavy chain of serum immunoglobulin $\mathrm{G}$ ( $\mathrm{Gm}$ allotypes) were determined by haemagglutination inhibition. ${ }^{11}$ Sera were typed for allotypic markers G1m(1), G1m(2), and G1m(3) on IgG1 and for G3m(5) on IgG3, as these markers can best characterise $\mathrm{Gm}$ phenotypes in Caucasian subjects. ${ }^{12}$ Serum immunoglobulin levels were determined by radial immunodiffusion in agar using commercial antisera. The frequency of genetic markers in patients with prolonged giardiasis was compared with that expected from large groups of healthy subjects. Comparison with patients having giardiasis of short duration was not possible, as only five adults in this group were identified during the two year period of study.

\section{MOUSE STUDIES}

Experiments were performed with male and female mice of the highly inbred strains $B A L B / C$ and $\mathrm{C} 3 \mathrm{H} / \mathrm{He}$ together with $\mathrm{BALB} / \mathrm{c} \times \mathrm{C} 3 \mathrm{H} / \mathrm{He} \mathrm{F}_{1}$ hybrids and backcross mice to $\mathrm{C} 3 \mathrm{H} / \mathrm{He}$. All mice were raised under specific pathogen-free conditions until 6 weeks of age and were then maintained under conventional conditions before, and during the course of experiments. Animals from this source have been found to be absolutely free of $G$. muris infection. Giardia cysts were isolated and quantified by a sucrose gradient method as described previously. ${ }^{13}$ Cysts were administered to recipient mice within seven days of transfer to conventional conditions and the subsequent excretion of cysts in stools was determined at intervals of one or two weeks in most experiments. The $\mathrm{H}-2$ haplotypes of backcross mice were determined by haemagglutination using antisera to $\mathrm{H}-2^{\mathrm{d}}$ and $\mathrm{H}-2^{\mathrm{k}}$ prepared by repeated injections of lymphoid cells into $\mathrm{H}-2$ incompatible recipients. ${ }^{14}$

\section{STATISTICS}

The Chi square test was used to compare the frequency of HLA antigens and Gm phenotypes in patient and control populations, while the relative risk was determined by the cross-product ratio. ${ }^{15}$ Giardia muris cyst counts in stools were expressed as a geometric mean and differences between groups were analysed by Student's $t$ test. All the P values were calculated to correspond to two-tailed tests of statistical significance.

\section{Results}

\section{HUMAN STUDIES}

Humoral immune deficiency was detected in eight patients (Table 1) but exclusion of this group had little influence on the frequency of various genetic markers and all patients have been included in statistical analyses.

\section{$A B O$ and Rhesus blood groups}

The frequency of $\mathrm{ABO}$ and Rhesus blood groups in patients with giardiasis was similar to expected frequencies from population data. Twenty-three patients were typed as blood group A (expected 20), five as blood group B (expected five), 18 as blood group 0 (expected 21), two as blood group AB (expected two), 42 as Rh-positive (expected 41), and six as Rh-negative (expected seven).

Comparison of ABO blood groups in patients with (36) and without (12) gastrointestinal symptoms showed an excess of blood group 0 in patients without symptoms (observed nine, expected four), and an excess of blood group $A$ in those with symptoms (observed 21, expected 15). However, groups will need to be larger before an association between $\mathrm{ABO}$ blood groups and the presence or absence of symptoms can be established.

\section{HLA typing}

HLA typing was performed in 46 patients and the results are shown in Table 2 . There was a higher than expected frequency of HLA-A1 and HLA-B12 and a lower than expected frequency of HLA-A3 and HLA-B35. In addition, patients had a higher than 
Table 2 Frequency of HLA antigens in 46 patients

\begin{tabular}{|c|c|c|c|c|c|}
\hline & \multicolumn{2}{|c|}{ Patients } & \multirow{2}{*}{$\begin{array}{l}\text { Controls } \\
(n=586) \\
(\%)\end{array}$} & \multirow[t]{2}{*}{$P^{*}$} & \multirow[t]{2}{*}{$R R_{\dagger}$} \\
\hline & (no.) & $(\%)$ & & & \\
\hline A1 & 21 & $46 \cdot 7$ & $32 \cdot 0$ & 0.05 & 1.86 \\
\hline A2 & 24 & $52 \cdot 2$ & $47 \cdot 1$ & - & - \\
\hline A3 & 4 & $8 \cdot 9$ & 24.9 & 0.02 & 0.29 \\
\hline A9 & 11 & $24 \cdot 4$ & $19 \cdot 3$ & - & - \\
\hline A 10 & 5 & $11 \cdot 1$ & $11 \cdot 9$ & - & - \\
\hline A11 & 4 & $8 \cdot 9$ & $12 \cdot 3$ & - & - \\
\hline A28 & 2 & $4 \cdot 4$ & $5 \cdot 6$ & - & - \\
\hline W19 complex & 3 & $6 \cdot 7$ & $5 \cdot 8$ & - & \\
\hline B5 & 4 & 8.9 & 8.9 & - & - \\
\hline B7 & 8 & $17 \cdot 8$ & $25 \cdot 3$ & - & - \\
\hline B8 & 11 & $24 \cdot 4$ & $26 \cdot 5$ & - & - \\
\hline B12 & 22 & $47 \cdot 8$ & $25 \cdot 8$ & 0.002 & $2 \cdot 64$ \\
\hline B13 & 1 & $2 \cdot 2$ & $5 \cdot 3$ & - & - \\
\hline B14 & 3 & $6 \cdot \overline{5}$ & 8.0 & - & - \\
\hline B15 & 5 & $11 \cdot 1$ & $5 \cdot 8$ & - & - \\
\hline B16 & 2 & $4 \cdot 4$ & $2 \cdot 2$ & - & - \\
\hline B 17 & 5 & $11 \cdot 1$ & $7 \cdot 2$ & - & - \\
\hline B18 & 2 & $4 \cdot 4$ & $3 \cdot 1$ & - & - \\
\hline B21 & 3 & $6 \cdot 7$ & - & - & - \\
\hline B22 & 1 & $2 \cdot 2$ & $5 \cdot 3$ & - & - \\
\hline B27 & 7 & $15 \cdot 6$ & $8 \cdot 2$ & NS & $2 \cdot 06$ \\
\hline B35 & 2 & $4 \cdot 4$ & $16 \cdot 2$ & 0.05 & $0 \cdot 24$ \\
\hline B40 & 3 & $6 \cdot 7$ & 11.9 & - & - \\
\hline
\end{tabular}

-Without correction for the number of antigens tested.

$\nmid$ Relative risk.

expected frequency of the phenotype A1/A2 (observed 12 , expected $\left.4.3, \chi^{2}=13.9, P<0.001\right)$ and the phenotype B12/B27 (observed six, expected $\left.0.5, \chi^{2}>50, P<0.001\right)$. The higher than expected frequency of HLA-A1 and HLA-B12 was observed in patients with and without gastrointestinal symptoms.

\section{Gm allotyping}

$\mathrm{Gm}$ allotypes were determined in 28 patients (Table 3) and the frequency of various phenotypes was similar to that in 1200 control subjects $\left(\chi^{2}=6 \cdot 9, \mathrm{P}>0 \cdot 1\right)$.

\section{MOUSE STUDIES}

The pattern of cyst excretion was evaluated in $23 \mathrm{~F}_{1} \times \mathrm{C} 3 \mathrm{H} / \mathrm{He}$ backcross mice, 15 males and eight

Table 3 Frequency of $\mathrm{Gm}$ phenotypes in 28 patients

\begin{tabular}{lll}
\hline & \multicolumn{2}{l}{ No. of patients } \\
\cline { 2 - 3 } Phenotype & Observed & Expected* \\
\hline Heterozygous & 6 & $8 \cdot 3$ \\
Gm 1, 3, 5 & 6 & $4 \cdot 1$ \\
Gm 1, 2, 3,5 & 2 & $1 \cdot 7$ \\
Uncertain & 4 & $1 \cdot 3$ \\
Gm 1, 2 & & $12 \cdot 6$ \\
Homozygous & 0 & 28.0 \\
Gm 1 3, 5 & 16 & \\
Totals & 28 & \\
\hline
\end{tabular}

Based on population frequencies. females, in an attempt to define the number of genes involved in resistance to $G$. muris. Mice were infected by the oral administration of 1000 cysts and the subsequent excretion of cysts in faeces was determined at weekly intervals for 12 weeks. Control groups consisted of eight male and female mice of strains BALB/c (a strain which shows rapid spontaneous resolution of infection), $\mathrm{C} 3 \mathrm{H} / \mathrm{He}$ (a strain which develops chronic giardiasis), and $\mathrm{BALB} / \mathrm{c} \times \mathrm{C} 3 \mathrm{H} / \mathrm{He} \mathrm{F}_{1}$ (which resemble $\mathrm{BALB} / \mathrm{c}$ mice in infection characteristics).

The majority of backcross mice showed a pattern of cyst excretion which more closely resembled the $\mathrm{C} 3 \mathrm{H} / \mathrm{He}$ than the $\mathrm{F}_{1}$ parental mice. However, only two of 15 backcross males resembled $\mathrm{C} 3 \mathrm{H} / \mathrm{He}$ males in showing a consistently high cyst output and only one of 15 males resembled $F_{1}$ males in showing a consistently low cyst output. The remaining mice showed cyst counts intermediate between the two groups. Similarly, intermediate patterns of cyst excretion were observed in all female backcross mice, although the group was relatively small. The data indicate that the ability to eliminate $G$. muris is influenced by several genes rather than one or two genes.

$\mathrm{H}-2$ haplotypes in backcross mice were determined, as BALB/c $\left(\mathrm{H}-2^{\mathrm{d}}\right)$ and $\mathrm{C} 3 \mathrm{H} / \mathrm{He}\left(\mathrm{H}-2^{\mathrm{k}}\right)$ mice are of different $\mathrm{H}-2$ haplotype. Eight of 15 males were typed as $\mathrm{k} / \mathrm{k}$ and $7 \mathrm{as} \mathrm{k} / \mathrm{d}$. No association was found between numbers of cysts excreted in faeces and the $k / k$ or $k / d$ haplotypes.

Throughout this study, female mice demonstrated more rapid elimination of infection than agematched male mice. The pattern of infection in genetically identical $\mathrm{C} 3 \mathrm{H} / \mathrm{He}, \mathrm{BALB} / \mathrm{c}$, and $\mathrm{BALB} / \mathrm{c} \times \mathrm{C} 3 \mathrm{H} / \mathrm{He} \mathrm{F}_{1}$ mice is shown in the Figure. In $\mathrm{C} 3 \mathrm{H} / \mathrm{He}$ mice, males had significantly higher cyst counts in faeces than females at weeks 4 $(\mathrm{P}<0.01), 6(\mathrm{P}<0.005), 8(\mathrm{P}<0.01)$, and $10(\mathrm{P}<0.05)$. In $B A L B / c$ and $F_{1}$ hybrids, differences between sexes did not reach statistical significance but after week 6 , cysts were absent from faeces in females but present in low numbers in some males.

\section{Discussion}

The demonstration of spontaneous resolution of $G$. lamblia in adult volunteers ${ }^{1}$ raises the possibility that transient infections, with or without gastrointestinal symptoms, are relatively common. Indeed, preliminary studies in our laboratory suggest that the majority of residents in Melbourne have detectable anti-Giardia antibody in serum (unpublished observations). Thus patients with persistent symptoms may constitute a relatively small group in whom spontaneous elimination is 


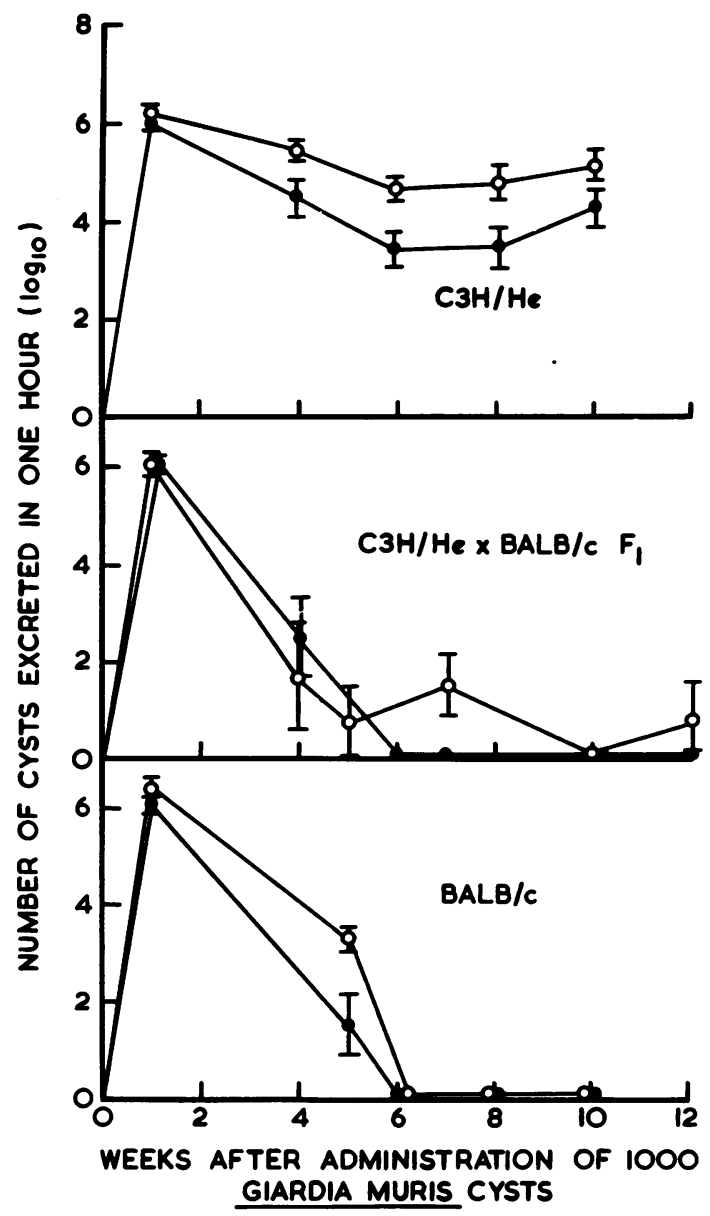

Figure Geometric mean numbers ( $\pm S E M)$ of Giardia cysts in stools over 10 to 12 weeks after oral administration of 1000 Giardia muris cysts to groups of male (O) and female (O) mice of strains $\mathrm{C} 3 \mathrm{H} / \mathrm{He}$, $\mathrm{C} 3 \mathrm{H} / \mathrm{He} \times \mathrm{BALB} / \mathrm{c} \mathrm{F}_{1}$, and $\mathrm{BALB} / \mathrm{c}$.

defective because of factors related to either the host or the parasite. Humoral immune deficiency has been clearly associated with prolonged and recurrent giardiasis (eight of 48 patients in this study) and cellular immune deficiency might have predisposed to prolonged infections in patients with Hodgkin's disease, cancer, chronic renal failure, and cirrhosis. Prior gastrectomy with hypochlorhydria may permit an excessive proliferation of trophozoites ${ }^{18}$ with inadequate control by local defence mechanisms. Protein-calorie malnutrition has been associated with prolonged giardiasis in tropical countries, ${ }^{17}$ perhaps because of co-existing suppression of immune mechanisms. Parasite factors might also be of importance, although antigenic variation or different serotypes of $G$. lamblia have not been identified.

Although some patients with immune defects were identified, the majority had normal serum immunoglobulin levels and otherwise appeared to enjoy good health. In contrast to previous studies, infected patients did not show an increased incidence of blood group A. However, previous studies were performed in children, presumably with gastrointestinal symptoms, and additional studies in patients, with and without symptoms, would be of interest (see Results section).

In the patient population there was a higher than expected frequency of the HLA antigens $A 1$ and B12 and of the phenotypes A1/A2 and B12/B27. HLA antigens or linked genes might be associated with a defective immune response to 'host-protective' antigens of $G$. lamblia and this possibility will be tested once sensitive assays for anti-Giardia antibody become available. Interestingly, HLA-B12 has been associated with specific immune responses to flagellar antigens (flagellin) from Salmonella adelaide. ${ }^{18}$

Genetic markers on human immunoglobulins (Gm allotypes) have not been extensively studied in infectious diseases, although particular allotypes have been associated with immune responses to immunisation with Haemophilus influenzae and Meningococcus polysaccharides ${ }^{18}$ and with immune responses after parenteral administration of flagellin. ${ }^{20}$

Study of the pattern of $G$. muris infection in backcross mice indicated that resistance to infection was influenced by several genes. Histocompatibility (H-2) genes did not appear to be involved, although the method of study would not permit detection of a minor influence of $\mathrm{H}-2$ type on the course of infection. Lower levels of infection were observed in female than in male mice-an effect which may be related to sex hormone levels ${ }^{21}$ or reflect the influence of loci associated with sex chromosomes. Variation in the natural history of infection between strains of mice does not appear to be related to serum levels of immunoglobulins ${ }^{22}$ or to serum levels of antibody to a crude sonicate of Giardia trophozoites (unpublished observations). The emergence of a relatively complex pattern of genetic control for a relatively simple intestinal protozan parasite emphasises the complexity of host responses to natural pathogens, in this case probably involving humoral and cell-mediated immune responses to several Giardia antigens as well as non-immunological defence mechanisms.

We are grateful to Dr A Dobrovic for HLA typing, to Dr D N Propert for Gm allotyping, to Dr J 
Layton for mouse histocompatibility (H-2) typing, and to Dr J D Mathews for assistance with statistical analyses.

\section{References}

'Rendtorff RC. The experimental transmission of human intestinal protozoan parasites. II. Giardia lamblia cysts given in capsules. Am J Hyg 1954; 59: 209-20.

'Webster BH. Human infection in Giardia lamblia. An analysis of thirty-two cases. Am J Dig Dis 1958; 3: 64-71.

${ }^{3}$ Alp MH, Hislop IG. The effect of Giardia lamblia infestation on the gastrointestinal tract. Aust Ann Med 1969; 18: 232-7.

'Webster ADB. The gut and immunodeficiency disorders. Clin Gastroenterol 1976; 5: 323-40.

${ }^{5}$ Yardley JH, Takano J, Hendrix TR. Epithelial and other mucosal lesions of the jejenum in giardiasis. Jejunal biopsy studies. Bull Johns Hopkins Hosp 1964; 115: 389-406.

${ }^{6}$ Barnes GL, Kay R. Blood groups in giardiasis (Letter). Lancet 1977; 1: 808.

${ }^{7}$ Zisman M. Blood group A and giardiasis (Letter). Lancet 1977; 2: 1285.

${ }^{8}$ Roberts-Thomson IC, Mitchell GF. Giardiasis in mice. I. Prolonged infections in certain mouse strains and hypothymic (nude) mice. Gastroenterology 1978; 75: 42-6.

${ }^{9}$ Kerlin P, Ratnaike RN, Butler R, Gehling N, Grant AK. Prevalence of giardiasis. A study at upper-gastrointestinal endoscopy. Am J Dig Dis 1978; 23: 940-2.

${ }^{10}$ Mittal KK, Mickey MR, Singal DP, Terasaki PI. Serotyping for homotransplantation. XVIII. Refinement of microdroplet lymphocyte cytotoxicity test. Transplantation 1968; 6: 913-27.

${ }^{1}$ Propert DN. Genetic markers in the blood of healthy subjects and patients with various mental disorders. Ph.D. thesis: The University of Melbourne, 1977.

${ }^{12}$ Schanfield MS. Genetic markers of human immunoglobulins. In: Basic and clinical immunology. Fundenberg HH, Sites DP, Caldwell JL, Wells JV, eds. Lange Medical Publications, Los Altos: 1976: 59-65.

${ }^{13}$ Roberts-Thomson IC, Stevens DP, Mahmoud AAF, Warren KD. Giardiasis in the mouse: an animal model. Gastroenterology 1976; 71 : 57-61.

${ }^{14}$ Brackertz D, Mitchell GF, Mackay IR. Antigeninduced arthritis in mice. I. Induction of arthritis in various strains of mice. Arthritis Rheum 1977; 20: 841-50.

${ }^{15}$ Svejgaard A, Jersild C, Nielsen LS, Bodmer WF. HL-A antigens and disease. Statistical and genetical considerations. Tissue Antigens 1974; 4: 95-105.

${ }^{16}$ Slonim JM, Ireton HJC, Smallwood RA. Giardiasis following gastric surgery. Aust $N Z J$ Med 1976; 6: 479-80.

${ }^{17}$ Mata LJ, Jiménez F, Cordón M, et al. Gastrointestinal flora in children with protein-calorie malnutrition. Am J Clin Nutr 1972; 25: 1118-26.

${ }^{18}$ Whittingham S, Mathews JD, Schanfield MS, et al. Interactive effect of Gm allotypes and HLA-B locus antigens on the human antibody response to a bacterial antigen 1979. Clin Exp Immunol 1980; 40: 8-15.

${ }^{19}$ Pandey JP, Fudenberg HH, Virella G, et al. Association between immunoglobulin allotypes and immune responses to Haemophilus influenzae and meningococcus polysaccharides. Lancet 1979; 1: 190-2.

${ }^{20}$ Wells JV, Fudenberg HH, Mackay IR. Relation of the human antibody response to flagellin to GM genotype. J Immunol 1971; 107: 1505-11.

${ }^{21}$ Eidinger D, Garrett TJ. Studies of the regulatory effects of the sex hormones on antibody formation and stem cell differentiation. J Exp Med 1972; 136: 1098-116.

${ }^{22}$ Natsuume-Sakai S, Motonishi K, Mitiga S. Quantitative estimations of five classes of immunoglobulin in inbred mouse strains. Immunology 1977; 32: 861-6. 